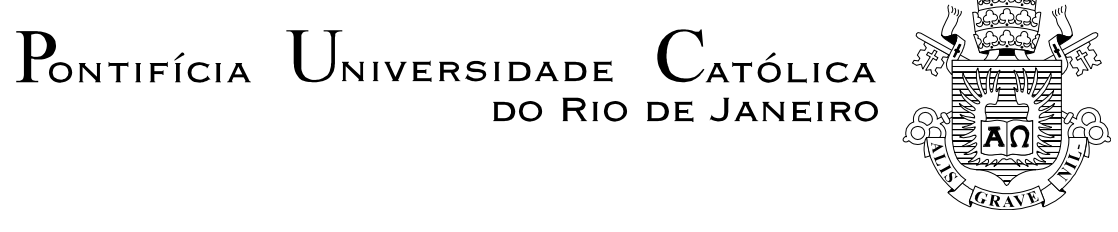

Kesia Guedes Arraes Gomes

\title{
Um método multicritério para localização de unidades celulares de intendência da FAB
}

\section{Dissertação de Mestrado}

Dissertação apresentada ao Programa de Pós-graduação em Engenharia de Produção da PUC-Rio como requisito parcial para obtenção do título de Mestre em Logística.

Orientador: Prof. Nélio Domingues Pizzolato

Rio de Janeiro Junho de 2009 


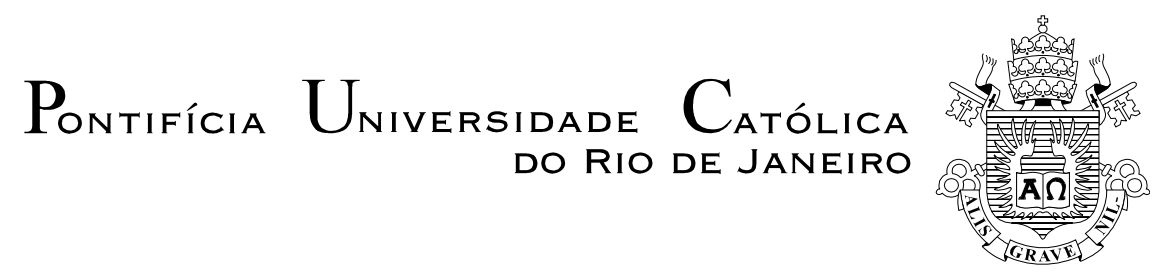

\title{
Kesia Guedes Arraes Gomes
}

\section{Um método multicritério para localização de unidades celulares de intendência da FAB}

Dissertação apresentada como requisito parcial para obtenção do grau de Mestre pelo Programa de PósGraduação em Engenharia de Produção da PUC-Rio. Aprovada pela Comissão Examinadora abaixo assinada.

\author{
Prof. Nélio Domingues Pizzolato \\ Orientador \\ Departamento de Engenharia Industrial - PUC-Rio
}

Prof. José Eugênio Leal Departamento de Engenharia Industrial - PUC-Rio

Prof. Rubens Teixeira da Silva TRANSPETRO

Prof. José Eugênio Leal Coordenador Setorial do Centro

Técnico Científico - PUC-Rio

Rio de Janeiro, 27 de junho de 2009 
Todos os direitos reservados. É proibida a repordução total ou parcial do trabalho sem autorização da universidade, da autora e do orientador.

\section{Kesia Guedes Arraes Gomes}

Graduou-se em Ciências Militares, pelo Curso de Formação de Oficiais Intendentes da Academia da Força Aérea, em Pirassununga, São Paulo, em 2000. Especializou-se em Tradução Inglês-Português pela PUC-Rio em 2006. Atuou como Ouvidora, Agente de Controle Interno e Chefe da Seção Administrativa da Diretoria de Intendência e da Seção de Inteligência durante os anos de 2002 a 2008. Trabalhou, ainda, na Divisão de Intendência Operacional, na Subdiretoria de Encargos Especiais, especificamente com o trato da Logística de Recursos Humanos da FAB. Em 2009, foi designada para cursar o mestrado em Gerenciamento Logístico, no AFIT - Air Force Institute of Technology, Base Aérea de Wright-Patterson, em Ohio, Estados Unidos.

Ficha Catalográfica

Gomes, Kesia Guedes Arraes

Um método multicritério para localização de unidades celulares de intendência da FAB / Kesia Guedes Arraes Gomes ; orientador: Nélio D. Pizzolato. - 2009.

v.,150 f. : il. ; $29,7 \mathrm{~cm}$

1. Dissertação (mestrado) - Pontifícia Universidade Católica do Rio de Janeiro, Departamento de Engenharia de Produção.

Inclui referências bibliográficas.

1. Engenharia de Produção - Teses. 2. Logística. 3. Teoria da Decisão. 4. Métodos multicriteriais. 5. Localização. 6. Método de Análise Hierárquica. 7. Unidades Celulares de Intendência da FAB. I. Pizzolato, Nélio D. II. Pontifícia Universidade Católica do Rio de Janeiro. Departamento de Engenharia de Produção. III. Título.

CDD: 658.5 


\section{Agradecimentos}

Ao meu orientador, Prof. Nélio Domingues Pizzolato, pelas observações sempre precisas e oportunas que muito me auxiliaram na elaboração deste trabalho.

Ao coordenador do curso de mestrado em logística, Prof. José Eugênio Leal, pelo apoio prestado durante todo o decorrer do curso e na defesa de minha dissertação.

Ao meu fiel amigo, Dr. Rubens Teixeira da Silva, pelo exemplo de vida e de perseverância e pelo apoio incondicional durante todo o decorrer de meu curso e desta dissertação.

Ao meu também fiel amigo, Cap Eng Carlos Zapff, pela ajuda irrestrita durante esta pesquisa, muito me auxiliando no manuseio do software utilizado. Não poderia deixar de ressaltar que tenho em grande estima nossa amizade, pela sinceridade com que compartilha suas idéias.

Ao meu amigo de sempre, Cel Av R1 Rodrigo Timótheo Machado Filho, a quem muito respeito e admiro.

Aos Diretores da DIRINT, Maj Brig Int Denizart Lustosa Ribeiro, Maj Brig Int Eliseu Mendes Barbosa e Maj Brig Int Pedro Norival de Araújo pela liderança e pelo voto de confiança a esta Oficial e aos jovens Oficiais Intendentes da Força Aérea Brasileira.

Aos amigos da Diretoria de Intendência pela contribuição na resposta aos questionários e, em especial, ao efetivo da Divisão de Intendência Operacional pelo intercâmbio de ideias tão inovadoras.

Aos meus familiares pela compreensão e incentivo. Em especial, agradeço ao meu pai por ter investido em mim desde o começo de minha vida e por vibrar a cada vitória.

Ao meu marido, Alan, e meu filho, Nicolas, por todo o apoio durante a realização do curso. Em especial, agradeço ao Alan por investir e acreditar em mim sempre. Esta conquista é para você.

Por fim e acima de tudo, agradeço a Deus por todas as oportunidades a mim ofertadas e pela saúde e fé para ultrapassar os obstáculos ao longo da caminhada. Exaltado seja o Seu nome! 


\section{Resumo}

Gomes, Kesia Guedes Arraes; Pizzolato, Nélio Rodrigues. Um método multicritério para localização de Unidades Celulares de Intendência da FAB. Rio de Janeiro, 2009. 150p. Dissertação de Mestrado - Departamento de Engenharia Industrial, Pontifícia Universidade Católica do Rio de Janeiro.

As Unidades Celulares de Intendência (UCI) da Força Aérea Brasileira são estruturas móveis destinadas a prestar o apoio logístico ao homem, quando deslocado de sua Organização Militar de origem, para cumprir missão real ou de adestramento, em locais remotos ou desprovidos de recursos. $\mathrm{Na} F A B$, existem oito UCI distribuídas regionalmente pelo território nacional brasileiro. Para atender ao Plano de Articulação da FAB e aos ditames da Estratégia Nacional de Defesa, vários estudos foram desenvolvidos, na Diretoria de Intendência, Órgão Central do Sistema de Intendência Operacional, acerca da sistemática de distribuição (localização) dessas Unidades para melhor atender às exigências operacionais da Força. Com o intuito de permitir uma maior compreensão sobre o tema, esta dissertação apresenta a aplicação de um método multicritério de apoio à decisão, denominado AHP (Analytic Hierarchy Process), com vistas a facilitar o processo de escolha e priorização da localização estratégica das UCI da FAB, contemplando o possível fechamento de três Unidades Celulares de Intendência. O método AHP, desenvolvido por Thomas L. Saaty, permite a estruturação hierárquica de um problema estratégico complexo, a incorporação das preferências dos decisores na mensuração dos fatores qualitativos envolvidos, bem como a aplicação de uma abordagem que pode agregar variáveis intangíveis monetariamente. A relevância do tema permitiu a participação de Oficiais da Diretoria de Intendência que são experientes e peritos no assunto, facilitando a captação das informações e dos dados necessários à aplicação do método.

\section{Palavras-chave}

Logística; Teoria da decisão; métodos multicriteriais; localização; Método de Análise Hierárquica; Unidades Celulares de Intendência da FAB 


\section{Abstract}

Gomes, Kesia Guedes Arraes; Pizzolato, Nélio Rodrigues (Advisor). A multicriteria method for the location of Intendancy Cellular Units of the Brazilian Air Force. Rio de Janeiro, 2009. 150p. Dissertação de Mestrado - Departamento de Engenharia Industrial, Pontifícia Universidade Católica do Rio de Janeiro.

The Intendancy Cellular Units (UCI) of the Brazilian Air Force are mobile structures which aim at providing the logistic support to man, when he's displaced from his Military Organization in order to accomplish real or training missions in remote areas or places that lack resources. In the Brazilian Air Force, there are eight UCI which are regionally distributed along the Brazilian national territory. Considering the need to fulfill the Brazilian Air Force Articulation Plan and the National Defense Strategy, many studies were developed in the Directory of Intendancy, Main Body that is responsible for the Operational Intendancy System, to evaluate the distribution (location) of these Units so as to comply with the operational demands of the Air Force. With the need to better understand the subject, this research presents the application of a multi-criteria decision making method, namely AHP (Analytic Hierarchy Process), to facilitate the process of choosing and prioritizing the UCI strategic location, taking into consideration the possible closure of three Intendancy Cellular Units. The AHP method, developed by Thomas L. Saaty, allows for the hierarchical structure of a complex strategic problem, the incorporation of decision makers preferences when measuring all the qualitative aspects involved as well as the use of an approach that can aggregate monetary intangible variables. Given the theme's relevance, the participation of wise and expert Officers from the Directory of Intendancy enabled the perception of information and the necessary data in order to apply the method.

\section{Keywords}

Logistics; Decision Theory; multi-criteria methods; location; Analytic Hierarchy Process; Intendancy Cellular Units of the Brazilian Air Force. 


\section{Sumário}

1 Introdução 12

1.1 Considerações iniciais sobre Unidades Celulares de Intendência 12

$\begin{array}{ll}1.2 \text { Objetivo da dissertação } & 17\end{array}$

1.3 Delimitação do escopo da dissertação 18

$\begin{array}{ll}1.4 \text { Metodologia } & 19\end{array}$

$\begin{array}{ll}1.5 \text { Estrutura da dissertação } & 20\end{array}$

2 Logística 21

2.1 Introdução 21

2.2 O papel da logística na FAB 22

2.2.1 Logística 22

2.2.2 Logística na Força Aérea Brasileira 24

2.2.3 Logística de Recursos Humanos 26

2.3 Sistema de Intendência Operacional 28

2.4 Política de Logística de Defesa 30

2.5 Apoio Logístico na FAB 33

2.5.1 A UCI na FAB 36

2.5.2 UCl e breve introdução à logística humanitária 39

2.5.3 UCl e breve introdução à Teoria da Localização 40

2.6 Conclusões do capítulo 42

3 Referencial Teórico 43

3.1 Introdução 43

3.2 Problema de Localização de Instalações - FLP 44

3.2.1 Modelos para Localização de Instalações 47

3.3 Análise da decisão 51

3.3.1 Histórico 51

3.3.2 Teoria da Decisão 52

3.4 Processo Decisório $\quad 55$

3.5 Paradigmas Científicos $\quad 57$

3.6 Análise Multicritério $\quad 59$ 
3.7 Métodos Muticritérios $\quad 60$

3.7.1 Classificação dos Métodos Multicritérios 60

3.7.2 Teoria da Utilidade Multiatributo 61

3.7.3 Métodos de sobreclassificação 62

3.7.4 Métodos interativos 63

3.7.5 Classificação quanto aos objetivos 63

3.7.6 Métodos multicriteriais contínuos e discretos 65

3.7.7 Problema de Decisão Multicritério 66

3.7.8 Escola Americana 67

3.7.9 Escola Francesa ou Européia 69

$\begin{array}{ll}3.8 \text { Conclusões do capítulo } & 70\end{array}$

4 O AHP

4.1 Introdução $\quad 72$

4.2 Razões para a escolha do AHP pelo pesquisador $\quad 72$

4.3 Método de Análise Hierárquica (AHP) 77

4.4 Base Teórica do AHP 78

4.4.1 Estruturação Hierárquica do Problema 80

4.4.2 Comparações par a par $\quad 82$

4.4.2.1 Escala Fundamental 83

4.4.3 Solução usando autovetores e autovalores $\quad 85$

4.4.3.1 Escalas de razão, proporcionalidade e escalas normalizadas $\quad 86$

4.4.4 Determinação da Consistência 89

4.4.5 Agregação das prioridades e escolha final 90

4.5 Decisões em grupo $\quad 91$

4.6 Análise de Sensibilidade $\quad 92$

4.6.1 Alteração dos pesos relativos dos critérios 93

4.6.2 Alteração dos julgamentos das alternativas 93

4.6.3 Alteração na quantidade de critérios $\quad 94$

4.6.4 Alteração na quantidade de alternativas 95

4.7 Solução de um problema simples usando o AHP 95

4.8 Principais críticas sobre o AHP 99

4.8.1 Conversãp de escala verbal para numérica 99

4.8.2 Inconsistências impostas pela Escala Fundamental 100 
4.8.3 Significado das respostas às questões $\quad 100$

4.8.4 Inversão do ranking das alternativas 100

4.8.5 Elevado número de comparações paritárias 101

4.8.6 Os axiomas do método 104

4.9 Conclusão

5 Aplicação do AHP à localização de UCI na FAB 105

5.1 Introdução 105

5.2 Hierarquia de critérios do problema de localização de UCI 105

5.3 As metodologias de análise de decisão vigentes na FAB 108

5.4 Estratégia Nacional de Defesa e Plano de Articulação da FAB 109

5.5 Objetivos Militares de Defesa 111

5.6 Diretrizes da Estratégia Nacional de Defesa 111

5.7 Aplicações do AHP $\quad 112$

5.8 Técnica SWOT 113

$5.9 \mathrm{UCl}$ da Base Aérea dos Afosnos (BAAF) 115

$5.10 \mathrm{UCl}$ da Base Aérea de Campo Grande (BACG) 116

$5.11 \mathrm{UCl}$ da Academia da Força Aérea (AFA) 117

$5.12 \mathrm{UCl}$ da Base Aérea de Canoas (BACO) 118

$5.13 \mathrm{UCl}$ da Base Aérea de Manaus (BAMN) 119

$5.14 \mathrm{UCl}$ da Base Aérea de Belém (BABE) 120

$5.15 \mathrm{UCl}$ do Depósito Central de Intendência (DCI) 121

$5.16 \mathrm{UCl}$ da Base Aérea de Recife (BARF) 122

5.17 Síntese dos resultados da aplicação do AHP 123

5.18 Exame dos resultados $\quad 126$

5.19 Considerações Finais $\quad 129$

6 Conclusão e contribuições 131

6.1 Conclusão 131

6.1 Contribuições 133

7 Referências Bibliográficas $\quad 134$

Apêndice A 143

Apêndice B 146 


\section{Lista de Figuras}

Figura 1 - Fotos de UCI da FAB 36

Figura 2 - Localização das UCI no território nacional 37

Figura 3 - Vantagens do método AHP 77

Figura 4 - Sequência do AHP $\quad 79$

Figura 5 - Exemplo de Estruturação Hierárquica 82

Figura 6 - Distribuição dos artigos por temas 103

Figura 7 - Distribuição dos artigos por áreas 103

Figura 8 - Representação da Hierarquia do problema de UCI - estágio $1 \quad 107$

Figura 9 - Representação da Hierarquia do problema de UCI - estágio $2 \quad 108$

Figura 10 - Estruturação Hierárquica 113

Figura 11 - Foto satélite da Base Aérea dos Afonsos 115

Figura 12 - Foto satélite da Base Aérea de Campo Grande 116

Figura 13 - Foto satélite da Academia da Força Aérea 117

Figura 14 - Foto satélite da Base Aérea de Canoas 118

Figura 15 - Foto satélite da Base Aérea de Manaus 119

Figura 16 - Foto satélite da Base Aérea de Belém 120

Figura 17 - Foto satélite do Depósito Central de Intendência 121

Figura 18 - Foto satélite da Base Aérea de Recife 122

Figura 19 - Resultado das alternativas por ordem prioritária 124

Figura 20 - Síntese do índice de inconsistência do cluster Critérios 125 


\section{Lista de Tabelas}

Tabela 1 - Características dos Paradigmas Racionalista e Construtivista 58

Tabela 2 - Escala de razão (Escala Fundamental de Saaty) 85

Tabela 3 - Valores de IC máximos em função da ordem da matriz 90

Tabela 4 - ICAs em função da ordem da matriz 90

Tabela 5 - Comparações par a par das alternativas segundo o critério Localização 96

Tabela 6 - Comparações par a par das alternativas segundo o critério Tipo da Missão 96

Tabela 7 - Comparações par a par das alternativas segundo o critério Aeronave 96

Tabela 8 - Comparações par a par dos critérios em relação ao objetivo principal 97

Tabela 9 - Síntese de Resultados 99

Tabela 10 - Análise SWOT para a BAAF 116

Tabela 11 - Análise SWOT para a BACG 117

Tabela 12 - Análise SWOT para a AFA 118

Tabela 13 - Análise SWOT para a BACO 119

Tabela 14 - Análise SWOT para a BAMN 120

Tabela 15 - Análise SWOT para a BABE $\quad 121$

Tabela 16 - Análise SWOT para o DCI 122

Tabela 17 - Análise SWOT para a BARF 123 